\title{
Polymerase chain reaction
}

\author{
BY JOHN K. CHESTERS \\ Biochemistry Division, Rowett Research Institute, Bucksburn, Aberdeen AB2 9SB
}

The polymerase chain reaction (PCR) is a technique for rapid amplification of a selected region of DNA, generally where the sequence at both $5^{\prime}$ and $3^{\prime}$ ends is known. In recent years it has been used for an extensive and ever-expanding range of biological applications, which include amplification of RNA sequences that have first been reverse-transcribed into DNA (RT-PCR).

\section{PRINCIPLE OF PCR}

PCR depends on generation of a deoxyoligonucleotide complementary to the known $3^{\prime}$ terminus of the portion of DNA to be amplified. This is then annealed with the appropriate strand of heat-denatured DNA and used as a primer for synthesis by a DNA polymerase of a full-length complementary strand (Fig. 1). The two strands are then separated by heat denaturation and the process repeated. However, included within the incubation mixture is a second primer capable of hybridizing to the $3^{\prime}$ end of the complementary strand of DNA. Thus, during cycles of denaturation, annealing and DNA extension, both the forward and reverse strands of the initial template DNA can act as templates for synthesis of new complementary strands. Since at the end of a cycle, each of the original complementary strands has generated its own complement, each
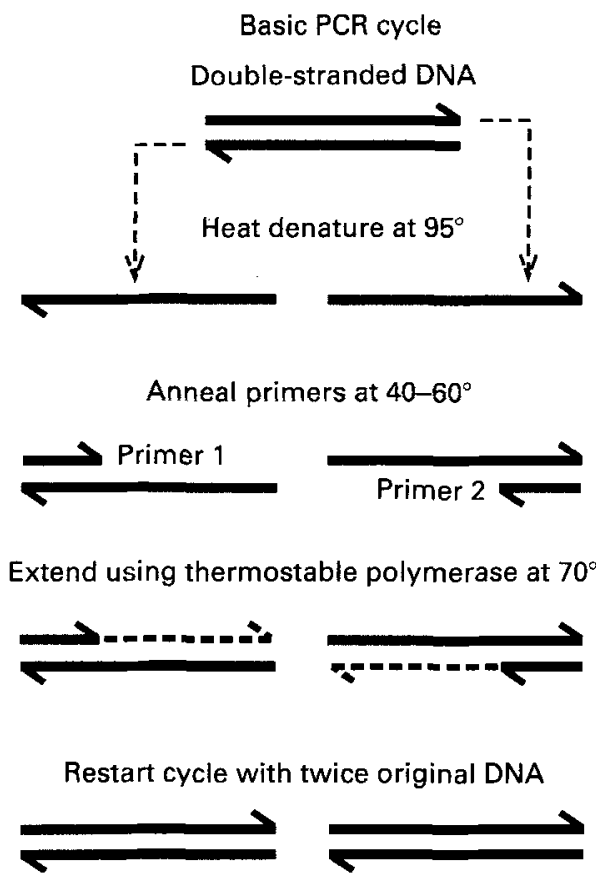

Fig. 1. Basic principle of DNA amplification during one polymerase-chain-reaction (PCR) cycle. 


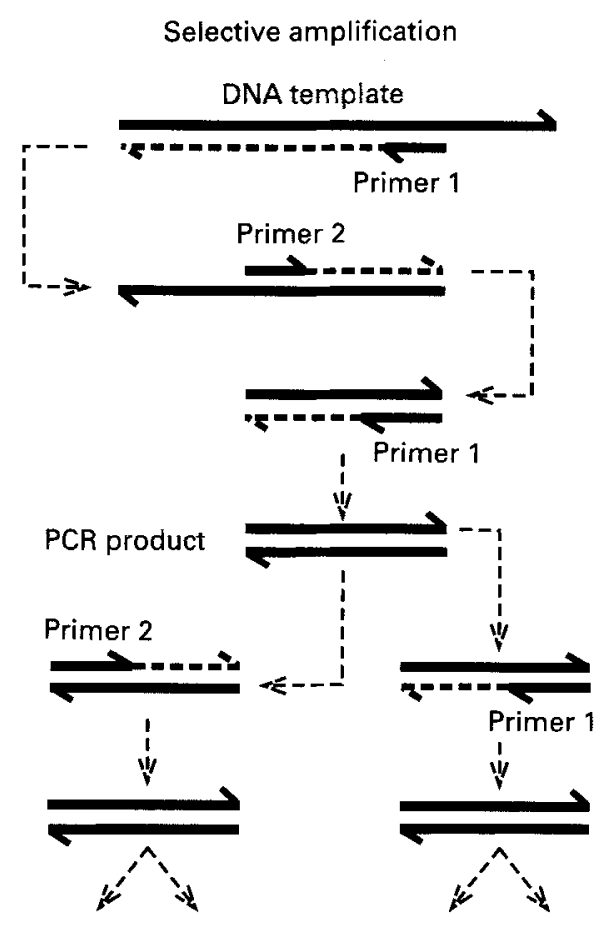

Fig. 2. Selective amplification of a section of DNA lying between two polymerase-chain-reaction (PCR) primers.

cycle doubles the quantity of amplified DNA present and the amplification proceeds logarithmically. Thus, theoretically thirty cycles of amplification would generate nearly $10^{9}$ times the original quantity of DNA.

The section of DNA amplified need only be a relatively small fraction of the initial template DNA. Thus, provided the DNA is accessible both to the primers and to the polymerase, small sections within a strand of chromosomal DNA can be selectively amplified with primers which anneal to the $3^{\prime}$ termini of the complementary strands of the section of interest (Fig. 2). Furthermore, the starting material may be RNA rather than DNA if the initial cycle utilizes a reverse transcriptase rather than DNA polymerase to extend the primer.

\section{APPLICATIONS}

Table 1 lists a selection of applications involving PCR which have relevance to nutritional studies. The technique may be used for preparation of labelled-DNA probes without having first to isolate the relevant section of the DNA from its plasmid or genomic DNA (Hirst et al. 1992). This can facilitate the production of probes for Northern- and Southern-blot analysis (see Kelly, 1996).

Families of genes having similar sequences can be investigated with generic primers often produced with a degree of in-built degeneracy which allows them to anneal to 
Table 1. Applications of polymerase chain reaction (PCR) and reverse-transcription $(R T)-P C R$

\begin{tabular}{|c|c|c|}
\hline Technique & Application & References \\
\hline PCR & $\begin{array}{l}\text { Synthesis of labelled-DNA probes } \\
\text { Molecular cloning } \\
\text { Sequencing DNA } \\
\text { Preparation of mutant DNA sequences } \\
\text { Screening transgenic bacteria and animals } \\
\text { Identification of sequence similarities } \\
\text { Identification of relationships within population } \\
\text { groups } \\
\text { Screening fetal characteristics }\end{array}$ & $\begin{array}{l}\text { Hirst et al. (1992) } \\
\text { Delidow (1993) } \\
\text { Meltzer (1993) } \\
\text { Chen \& Przybyla (1994) } \\
\text { Witsell \& Shook (1993) } \\
\text { Pellegrino \& Berg (1991); Preston (1993) } \\
\text { Chen \& Evans (1993) } \\
\text { Langlois \& Wilson (1993) }\end{array}$ \\
\hline RT-PCR & $\begin{array}{l}\text { Detection of rare mRNA } \\
\text { Survey of tissue or cell distribution of mRNA } \\
\text { Detection of variations in patterns of iso- } \\
\text { protein expression } \\
\text { Quantification of mRNA and pre-mRNA } \\
\text { Determination of mRNA and, hence, amino } \\
\text { acid sequences }\end{array}$ & $\begin{array}{l}\text { Greco (1993); Witsell \& Shook (1993) } \\
\text { Volkenandt et al. (1992); Kelley et al. (1993) } \\
\text { Bottema \& Sommer (1993) } \\
\text { Lipson \& Baserga (1989); Volkenandt et al. } \\
\quad \text { (1992) } \\
\text { Meltzer (1993) }\end{array}$ \\
\hline
\end{tabular}

regions not identical but closely conserved within the family (Preston, 1993). The portions of the genes lying between these conserved regions can then be amplified and their structure determined. Thus, the genes for proteins with similar function, for example the 'zinc-finger' proteins (Pellegrino \& Berg, 1991) or equivalent proteins from different species can be identified. It is also possible to use PCR to generate mutations and this can provide a useful tool for the elucidation of structure-function relationships (Chen \& Przybyla, 1994).

The ability to amplify to usable levels DNA obtainable in only minute amounts from small blood samples means that it is feasible to assess the genetic profile of relatively large numbers of individuals (Chen \& Evans, 1993). This should provide opportunities for the analysis of the influence of genetic factors on responses to nutrients and the relative contributions of genetics $v$. nutrition to the incidence of a range of conditions such as coronary disease and susceptibility to malignancy. The ability to analyse trace quantities of DNA has been used also to assess the genetic make up of a fetus during gestation by analysing the very small proportion of fetal cells circulating in maternal blood (Langlois \& Wilson, 1993).

PCR is also extensively used in sequencing DNA, including cDNA, thus providing the amino acid sequences of the corresponding proteins (Meltzer, 1993). In contrast to most PCR reactions only a single primer is used for sequencing reactions, so that only the strand of interest is amplified and labelled before its analysis. The resulting amplification is linear with cycle number rather than logarithmic and the technique requires a higher initial DNA concentration than is commonly employed with standard PCR.

RT-PCR, transcription of RNA into DNA before its amplification by PCR, permits detection of mRNA as well as DNA (Volkenandt et al. 1992; Kelley et al. 1993). The sensitivity of this technique means that investigation of mRNA expression is possible even where the material available is extremely limited, as for example during studies of 
embryonic development (Greco, 1993) or when screening cell lines during cloning (Witsell \& Shook, 1993). It is also possible to investigate the primary product of transcription even though relatively rapid splicing ensures that it may be present at a concentration well below that of the corresponding mRNA (Lipson \& Baserga, 1989). Furthermore, if the primers are carefully chosen to span regions of difference, it is often possible to distinguish closely-related mRNA such as those associated with isoenzymes or tissue-specific transporter proteins (Bottema \& Sommer, 1993). As well as detecting the presence of specific mRNA, it is possible to obtain quantitative estimates, although the high degrees of amplification generally implicit in the use of PCR require special consideration in order to provide valid data (Volkenandt et al. 1992; see also below).

\section{EXPERIMENTAL CONSIDERATIONS}

Although previously recognized, PCR has only been widely applicable since thermostable DNA polymerases became available. A typical cycle of amplification involves heat denaturation at $95^{\circ}$ to separate the strands, annealing at $40-60^{\circ}$ and primer extension at $72^{\circ}$ (Fig. 1). The denaturation step inactivated the polymerases initially employed, which then had to be added afresh during each cycle rendering the process laborious and expensive. However, currently-available thermostable polymerases, of which Taq was the first and still the most commonly used, are capable of retaining activity for up to thirty to forty cycles. This allows incubation mixtures containing all four deoxynucleotides, the two oligonucleotide primers and the polymerase to undergo multiple rounds of amplification in a programmable thermocycler without manual intervention.

The fundamental simplicity of the present methodology means that large numbers of samples can be processed in parallel but several factors must be considered for the results to be of value, one major consideration being the choice of primers. These oligonucleotides are now readily prepared by chemical synthesis. However, they must be chosen to form reasonably stable hybrids at the site of interest and their sequence should preclude binding to other sites within the template (Bloch, 1991; Erlich et al. 1991). Furthermore, they must not hybridize with the second PCR primer nor should they be liable to self-hybridize, since each of these conditions would result mainly in the production of short lengths of DNA containing primer dimers. Computer programs are now available to aid selection of suitable primers which are generally twenty to thirty nucleotides long. Success with PCR also depends on optimizing the Mg concentration in the reaction mixture which can influence both the extent and specificity of the reaction.

If the aim is simply to detect the presence of specific DNA or mRNA or to produce substantial quantities of a specific DNA, development of a satisfactory system is generally relatively straightforward. However, where quantitative results are important, considerable thought and technical expertise is often required. By the nature of PCR, amplification occurs logarithmically. Thus, small differences in amplification efficiency between samples and within samples between cycles will result in substantial variation in the yield of product. A variety of strategies have been developed to minimize these difficulties. Parallel amplification of standards is not generally satisfactory because of inter-sample variation and methods based on internal standardization are preferable (Volkenandt et al. 1992). These may involve amplification of a known amount of a second product using its own separate primers, but variations in efficiency of amplification between primers limit the usefulness of this technique (Khan et al. 1992). A more 
satisfactory approach involves amplification of an internal standard with the same primers used with the experimental DNA (Van den Heuvel et al. 1993). In this case, however, the products of amplification of the experimental and standard DNA must be distinguishable generally by electrophoretic separation. The internal standard may be designed to yield a different length product, but possibly the most elegant approach is to use a version of the experimental sequence mutated such that it lacks or contains an extra restriction site (Gilliland et al. 1990). In this case, the experimental and standard templates may differ by only one or two bases and are amplified under identical conditions yet they can be separately estimated after electrophoresis of the restricted products.

PCR is increasingly utilized to detect and estimate mRNA by first reverse transcribing them into DNA. However, the complementary DNA (cDNA) so formed closely resemble sections of the chromosomal DNA and trace contamination of the RNA with the latter can totally invalidate the technique. Various strategies have been developed to minimize this problem. Thus, the two primers can be chosen to hybridize with different exons yielding products from genomic DNA containing intron sequences which can be separated by size from the mRNA products which lack these sequences (Chelly et al. 1990). Use is also commonly made of the poly A tail present in most mRNA but not in the genomic DNA to prime RT-PCR with oligonucleotides containing poly dT (Moore et al. 1990). Alternatively reverse transcription may be primed with a sequence specific at its $3^{\prime}$ end to the mRNA of interest but having a $5^{\prime}$ sequence not naturally present in the DNA (Shuldiner et al. 1991). The subsequent PCR reactions are then primed with sequences matching this unique $5^{\prime}$ sequence since these will only be present in the products of reverse transcription of mRNA.

\section{CONCLUSIONS}

The many variants of PCR provide an extremely powerful range of techniques for the investigation of biological samples but their very potential to amplify minute traces of DNA requires extreme care to be exercised in their execution and interpretation.

\section{REFERENCES}

Bloch, W. (1991). A biochemical perspective of the polymerase chain reaction. Biochemistry 30, $2735-2747$.

Bottema, C. D. \& Sommer, S. S. (1993). PCR amplification of specific alleles: rapid detection of known mutations and polymorphisms. Mutation Research 288, 93-102.

Chelly, J., Montarras, D., Pinset, C., Berwaldnetter, Y., Kaplan, J. C. \& Khan, A. (1990). Quantitative estimation of minor messenger RNAs by cDNA polymerase chain reaction - application to dystrophin messenger RNA in cultured myogenic and brain cells. European Journal of Biochemistry 187, 691-698.

Chen, B. \& Przybyla, A. E. (1994). An efficient site-directed mutagenesis method based on PCR. Biotechniques 17, 657-659.

Chen, S. \& Evans, G. A. (1993). Use of the polymerase chain reaction for screening transgenic mice. In $P C R$ Protocols, pp. 75-81 [B. A. White, editor]. New Jersey: Humana Press.

Delidow, B. C. (1993). Molecular cloning of polymerase chain reaction fragments with cohesive ends. In $P C R$ Protocols, pp. 217-228 [B. A. White, editor]. New Jersey: Humana Press.

Erlich, H. A., Gelfand, D. \& Sninsky, J. J. (1991). Recent advances in the polymerase chain reaction. Science 252, 1643-1651.

Gilliland, G., Perrin,-S., Blanchard, K. \& Bunn, H. F. (1990). Analysis of cytokine messenger RNA and DNA - detection and quantitation by competitive polymerase chain reaction. Proceedings of the National Academy of Sciences, USA 87, 2725-2729. 
Greco, T. L., Duello, T. M. \& Gorski, J. (1993). Estrogen receptors, estradiol, and diethylstilbestrol in early development: the mouse as a model for the study of estrogen receptors and estrogen sensitivity in embryonic development of male and female reproductive tracts. Endocrinology Reviews 14, 59-71.

Hirst, M. C., Bassett, J. H. D., Roche, A. \& Davies, K. E. (1992). Preparation of radiolabelled hybridization probes by STS labelling. Trends in Genetics 8, 6-7.

Kelley, M. R., Jurgens, J. K., Tentler, J., Emanuele, N. V., Blutt, S. E. \& Emanuele, M. A. (1993). Coupled reverse transcription-polymerase chain reaction (RT-PCR) technique is comparative, quantitative and rapid: uses in alcohol research involving low abundance mRNA species such as hypothalamic LHRH and GRF. Alcohol 10, 185-189.

Kelly, K. F. (1996). Southern blotting. Proceedings of the Nutrition Society 55, 591-597.

Khan, I., Tabb, T., Garfield, R. E. \& Grover, A. K. (1992). Polymerase chain reaction assay of messenger RNA using 28S rRNA as internal standard. Neuroscience Letters 147, 114-117.

Langlois, S. \& Wilson, R. D. (1993). Non-invasive prenatal fetal testing by analysis of maternal blood. Clinical and Investigative Medicine 16, 333-338.

Lipson, K. E. \& Baserga, R. (1989). Transcriptional activity of the human thymidine kinase gene determined by a method using the polymerase chain reaction and an intron-specific probe. Proceedings of the National Academy of Sciences, USA 86, 9774-9777.

Meltzer, S. J. (1993). Direct sequencing of polymerase chain reaction products. In PCR Protocols, pp. 137-141 [B. A. White, editor]. New Jersey: Humana Press.

Moore, R. E., Shepherd, J. W. \& Hoskins, J. (1990). Design of PCR primers that detect only messenger RNA in the presence of DNA. Nucleic Acids Research 18, 1921.

Pellegrino, G. R. \& Berg, J. M. (1991). Identification and characterization of zinc-finger domains by the polymerase chain reaction. Proceedings of the National Academy of Sciences, USA 88, 671-675.

Preston, G. M. (1993). Use of degenerate oligonucleotide primers and the polymerase chain reaction to clone gene family members. In PCR Protocols, pp. 317-337 [B. A. White, editor]. New Jersey: Humana Press.

Shuldiner, A. R., Tanner, K., Moore, C. A. \& Roth, J. (1991). RNA template-specific PCR an improved method that dramatically reduces false positives in RT-PCR. Biotechniques 11, 760-763.

Van den Heuvel, J. P., Tyson, F. L. \& Bell, D. A. (1993). Construction of recombinant RNA templates for use as internal standards in quantitative RT-PCR. Biotechniques 14, 395-398.

Volkenandt, M., Dicker, A. P., Banerjee, D., Fanin, R., Schweizter, B., Holikoshi, T., Danenberg, K., Danenberg, P. \& Bertino, J. R. (1992). Quantitation of gene copy number and messenger RNA using the polymerase chain reaction. Proceedings of the Society for Experimental Biology and Medicine 200, 1-6.

Witsell, A. L. \& Shook, L. B. (1993). Utilization of polymerase chain reaction for clonal analysis of gene expression. In PCR Protocols, pp. 199-204 [B. A. White, editor]. New Jersey: Humana Press. 